\title{
Clinicopathologic Characteristics of Breast Cancer According to the Infiltrating Immune Cell Subtypes
}

\author{
Hye Min Kim and Ja Seung Koo * \\ Department of Pathology, Yonsei University College of Medicine, Seoul 03722, Korea; pinkmin15@yuhs.ac \\ * Correspondence: kjs1976@yuhs.ac; Tel.: +82-2-2228-1772
}

Received: 26 May 2020; Accepted: 19 June 2020; Published: 22 June 2020

\begin{abstract}
The clinical significance of immune cell subtypes in breast cancer remains poorly understood. To identify tumor-infiltrating immune cell subtypes in breast cancer and investigate their implications, tissue microarrays were constructed using 334 cases of invasive ductal carcinoma (luminal A type: $162(48.5 \%)$, luminal B type: 96 (28.7\%), HER-2 type: 21 (6.3\%), and triple negative breast cancer: $55(16.5 \%)$ ). Hormone receptors (ER, PR, and HER-2), Ki-67, and immune cell subtype-related proteins (STAT4, STAT6, FOXP3, CD8, CD68, and CD163) were assessed immunohistochemically. The proportion of highly expressed STAT6, FOXP3, CD8, CD68, and CD163 proteins was found to be lowest in luminal A type but highest in the HER-2 type. Additionally, high-level STAT6, FOXP3, CD68, and CD163 protein expression was associated with higher histologic grade. ER negativity was associated with high STAT6, FOXP3, and CD163 expression levels, whereas PR negativity and high Ki-67 labeling index were associated with high CD163 expression. Univariate $(p=0.003)$ and multivariate Cox (hazard ratio: 2.435, 95\% CI: 1.110-5.344, $p=0.049$ ) analyses showed that high CD8 expression is an independent factor associated with shorter disease-free survival. Immune cell subtype-related protein expression is dependent on breast cancer molecular subtypes, and CD8 expression is associated with patient prognosis.
\end{abstract}

Keywords: breast cancer; tumor microenvironment; infiltrating immune CD8 cells; prognosis

\section{Introduction}

Stromal cells, comprising the tumor microenvironment (TME), can be divided into the following types: cancer-associated fibroblast, angiogenic vascular cells, and infiltrating immune cells [1]. These components influence tumor growth and progression through various cross-talks with cancer cells. The infiltrating immune cells are comprised of dendritic cells, T-cells, macrophages, myeloid derived suppressor cells, and natural killer cells [2]. Accumulating evidence emphasizes that tumor infiltrating lymphocytes (TILs), including naïve $\mathrm{T}$ cells, effector $\mathrm{T}$ cells, and memory $\mathrm{T}$ cell subtypes plays a crucial role in the TME by exerting anti-tumor activity, whereas tumor-associated macrophages are responsible in promoting cancer progression [3-5]. Even though various markers have been proposed to assess $\mathrm{T}$ cells and macrophages, it has been traditionally regarded that STAT4, STAT6, FOXP3, and CD8 represents $\mathrm{T}$ helper (Th) 1, Th 2, regulatory $\mathrm{T}$ cell, cytotoxic $\mathrm{T}$ cell related marker, while CD68 and CD163 are suggested to be a marker of M1 and M2 macrophages [6-10].

Breast cancer is a histologically heterogenous tumor that typically presents with immune cell deposition in the TME. It is noteworthy that the WHO (World Health Organization) classification of tumors classifies individual histological subtypes with high immune cell infiltration as medullary carcinoma, atypical medullary carcinoma, or invasive carcinoma with medullary features [11]. Specifically, the molecular subtypes of breast cancer that are reported to be associated with abundant immune cell infiltration are HER-2 rich type and basal-like type/triple negative breast cancer [12]. In a previous study, TIL was shown to be associated with complete chemotherapy responses in 
HER-2-positive and triple negative breast cancer [13]. Moreover, TIL was found to be related to longer survival after adjuvant chemotherapy in TNBC [14]. Additionally, a study by Liu et al. demonstrated that the infiltration of $\mathrm{CD}^{+}$lymphocytes is an independent prognostic factor in basal-like breast cancer [15]. Therefore, although TILs are thought to play an important role in breast cancer, previous studies on TIL have only focused on evaluating phenotypes using CD markers of CD4 and CD8 in invasive ductal carcinoma. Moreover, even though there are studies that investigated markers of FOXP3, CD163, and CD68, investigations have been only performed in pathologic subtypes of ductal carcinoma in situ, and the clinical relevance of immune cell subtypes has been poorly studied [15-20]. Therefore, the purpose of this study was to identify subtypes of tumor-infiltrating immune cells in breast cancer and to investigate their implications.

\section{Results}

\subsection{Basal Characteristics of Breast Cancer Patients}

Of the 334 cases studied, 162 (48.5\%), 96 (28.7\%), 21 (6.3\%), and 55 (16.5\%) cases were luminal A, luminal B, HER-2 type, and triple negative breast cancer, respectively. The clinicopathologic features based on the breast cancer molecular subtypes are shown in Supplementary Table S1. The histologic grade was significantly different based on the molecular subtype $(p<0.001)$; however, there was no difference based on age, tumor stage, and nodal stage. The ratio of lymphocyte predominant breast cancer (LPBC) was significantly lower in luminal A type compared to those in other subtypes $(p<0.001)$.

\subsection{Expression of Immune Cell Subtype-Related Proteins According to the Breast Cancer Molecular Subtype}

Representative images of the expression of immune cell subtype-related proteins according to the breast cancer molecular subtype are shown in Figure 1. The median values of the expression levels of immune cell subtype-related proteins were as follows: STAT4 h-score: 90, STAT6 h-score: 0, FOXP3: 0, CD8: 5, CD68: 0, and CD163: 10. Next, we classified the values below and above the median level as low and high expression, respectively, and compared the expression of each molecule among the breast cancer molecular subtypes. Consequently, the frequencies of high expression of STAT6 $(p=0.047)$, FOXP3 $(p=0.006), \operatorname{CD} 8(p<0.001)$, CD68 $(p=0.026)$, and CD163 $(p<0.001)$ proteins were found to be lowest in the luminal A type, while high expression of these proteins was more frequent in the HER-2 type (Table 1). On comparing the number of immune cells expressing immune cell subtype-related proteins, we found that the expression of STAT6 $(p=0.005), \operatorname{FOXP3}(p=0.001)$, CD8 $(p=0.012), \operatorname{CD} 68(p=0.011)$, and CD163 $(p<0.001)$ differed significantly according to the breast cancer molecular subtypes. The proportions of immune cells expressing STAT6, FOXP3, CD8, CD68, and CD163 were the lowest in luminal A and highest in HER-2 type (Table 2).

Among the 334 cases, the proportion of highly expressed immune cell subtype-related proteins was significantly higher in LPBC cases $(p<0.05)$. In an LPBC subgroup analysis, and according to the molecular subtype, we observed a significantly higher proportion of highly expressed CD8 $(p<0.001)$, CD68 $(p=0.003)$, and CD163 $(p<0.001)$ in luminal A type; STAT6 $(p=0.016), \operatorname{CD} 8(p<0.001)$, CD68 $(p=0.002)$, and CD163 $(p=0.001)$ in luminal B type; STAT4 $(p=0.041)$ and CD8 $(p=0.002)$ in HER-2 type; and STAT4 $(p=0.021), \operatorname{CD} 8(p=0.005), \operatorname{CD} 68(p=0.023)$, and CD163 $(p=0.023)$ in TNBC (Table 3$)$. 


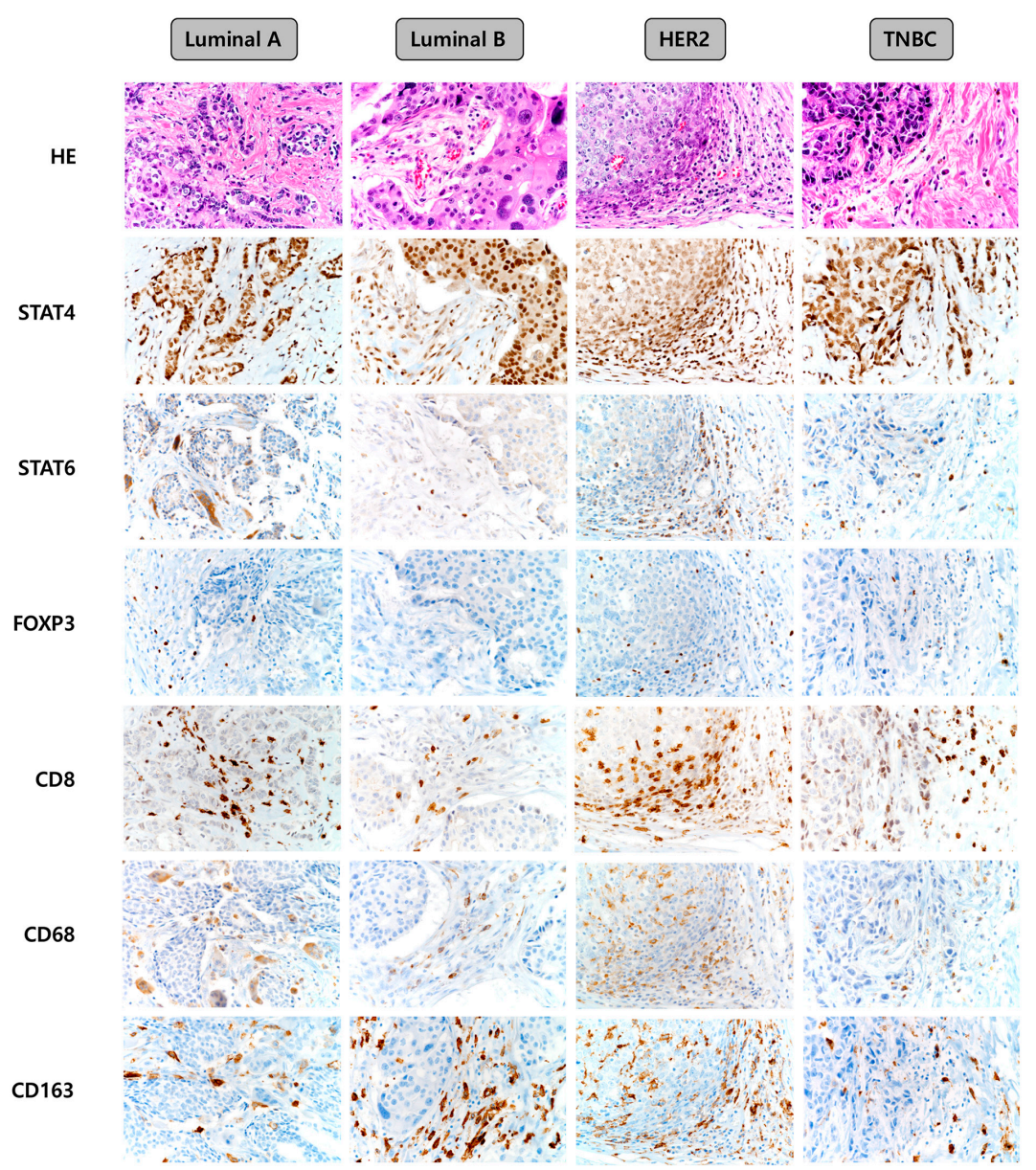

Figure 1. Representative images of immune cell subtype-related protein expression according to the breast cancer molecular subtypes. TNBC, triple-negative breast cancer.

Table 1. Expression of immune cell subtype-related proteins according to the breast cancer molecular subtype (Low versus High).

\begin{tabular}{|c|c|c|c|c|c|c|}
\hline Parameter & $\begin{array}{c}\text { Total } \\
(n=334) \\
(\%)\end{array}$ & $\begin{array}{c}\text { Luminal A } \\
(n=162) \\
(\%)\end{array}$ & $\begin{array}{c}\text { Luminal B } \\
\quad(n=96) \\
(\%)\end{array}$ & $\begin{array}{c}\text { HER-2 } \\
(n=21) \\
(\%)\end{array}$ & $\begin{array}{c}\text { TNBC } \\
(n=55) \\
(\%)\end{array}$ & $p$-Value \\
\hline STAT4 & & & & & & 0.809 \\
\hline Low & $237(71.0)$ & $115(71.0)$ & $71(74.0)$ & $14(66.7)$ & 37 (67.3) & \\
\hline High & $97(29.0)$ & $47(29.0)$ & $25(26.0)$ & $7(33.3)$ & $18(32.7)$ & \\
\hline STAT6 & & & & & & 0.047 \\
\hline Low & $252(75.4)$ & $131(80.9)$ & 65 (67.7) & $13(61.9)$ & $43(78.2)$ & \\
\hline High & $82(24.6)$ & $31(19.1)$ & $31(32.3)$ & $8(38.1)$ & $12(21.8)$ & \\
\hline FOXP3 & & & & & & 0.006 \\
\hline Low & $300(89.8)$ & $151(93.2)$ & 88 (91.7) & $15(71.4)$ & $46(83.6)$ & \\
\hline High & $34(10.2)$ & $11(6.8)$ & $8(8.3)$ & $6(28.6)$ & $9(16.4)$ & \\
\hline CD8 & & & & & & $<0.001$ \\
\hline Low & $292(87.4)$ & 155 (95.7) & $78(81.3)$ & $12(57.1)$ & 47 (85.5) & \\
\hline High & $42(12.6)$ & $7(4.3)$ & 18 (18.8) & $9(42.9)$ & $8(14.5)$ & \\
\hline CD68 & & & & & & 0.026 \\
\hline Low & $183(54.8)$ & $101(62.3)$ & $48(50.0)$ & $7(33.3)$ & 27 (49.1) & \\
\hline High & $151(45.2)$ & $61(37.7)$ & $48(50.0)$ & $14(66.7)$ & $28(50.9)$ & \\
\hline CD163 & & & & & & $<0.001$ \\
\hline Low & $223(66.8)$ & $131(80.9)$ & $57(59.4)$ & $8(38.1)$ & $27(49.1)$ & \\
\hline High & $111(33.2)$ & 31 (19.1) & 39 (40.6) & $13(61.9)$ & $28(50.9)$ & \\
\hline
\end{tabular}

TNBC: triple-negative breast cancer. 
Table 2. Expression of immune cell subtype-related proteins according to the breast cancer molecular subtype (H-score or \%).

\begin{tabular}{ccccccc}
\hline Parameter & $\begin{array}{c}\text { Total } \\
(n=334) \\
(\text { Mean } \pm \text { SD) }\end{array}$ & $\begin{array}{c}\text { Luminal A } \\
(\boldsymbol{n}=\mathbf{1 6 2}) \\
(\mathbf{M e a n} \pm \mathbf{S D})\end{array}$ & $\begin{array}{c}\text { Luminal B } \\
(\boldsymbol{n}=\mathbf{9 6}) \\
(\mathbf{M e a n} \pm \mathbf{S D})\end{array}$ & $\begin{array}{c}\text { HER-2 } \\
(\boldsymbol{n}=\mathbf{2 1}) \\
(\mathbf{M e a n} \pm \mathbf{S D})\end{array}$ & $\begin{array}{c}\text { TNBC } \\
(\boldsymbol{n}=\mathbf{5 5})\end{array}$ & $\boldsymbol{p}$-Value \\
(Mean \pm SD) & \\
\hline STAT4 H-score & $87.7 \pm 56.6$ & $87.8 \pm 53.6$ & $81.8 \pm 55.3$ & $102.8 \pm 65.0$ & $92.0 \pm 64.0$ & 0.417 \\
STAT6 H-score & $2.6 \pm 7.3$ & $1.5 \pm 3.9$ & $3.5 \pm 8.1$ & $7.1 \pm 16.3$ & $2.7 \pm 7.9$ & 0.005 \\
FOXP3 (\%) & $0.5 \pm 1.5$ & $0.3 \pm 1.2$ & $0.4 \pm 1.3$ & $1.6 \pm 2.8$ & $0.8 \pm 1.8$ & 0.001 \\
CD8 (\%) & $6.3 \pm 7.9$ & $5.2 \pm 5.3$ & $7.6 \pm 9.6$ & $10.2 \pm 8.1$ & $6.1 \pm 10.1$ & 0.012 \\
CD68 (\%) & $1.0 \pm 1.9$ & $0.7 \pm 1.6$ & $1.0 \pm 1.7$ & $1.4 \pm 2.4$ & $1.7 \pm 2.7$ & 0.011 \\
CD163 (\%) & $14.6 \pm 15.6$ & $9.7 \pm 11.7$ & $17.4 \pm 17.1$ & $22.1 \pm 17.4$ & $21.4 \pm 17.9$ & $<0.001$ \\
\hline
\end{tabular}

TNBC: triple-negative breast cancer; SD: standard deviation. 
Table 3. Expression of immune cell subtype-related proteins in molecular subtypes of breast cancer based on LPBC status.

\begin{tabular}{|c|c|c|c|c|c|c|c|c|c|c|c|c|c|c|c|}
\hline \multirow{2}{*}{ Parameter } & \multicolumn{3}{|c|}{ Total breast cancer } & \multicolumn{3}{|c|}{ Luminal A } & \multicolumn{3}{|c|}{ Luminal B } & \multicolumn{3}{|c|}{ HER-2 } & \multicolumn{3}{|c|}{ TNBC } \\
\hline & $\begin{array}{c}\text { No LPBC } \\
n=292(\%)\end{array}$ & $\begin{array}{c}\text { LPBC } \\
n=42(\%)\end{array}$ & $p$-Value & $\begin{array}{c}\text { No LPBC } \\
n=154(\%)\end{array}$ & $\begin{array}{c}\text { LPBC } \\
n=8(\%)\end{array}$ & $p$-Value & $\begin{array}{r}\text { No LPBC } \\
n=81(\%)\end{array}$ & $\begin{array}{c}\text { LPBC } \\
n=15(\%)\end{array}$ & $p$-Value & $\begin{array}{r}\text { No LPBC } \\
n=13(\%)\end{array}$ & $\begin{array}{c}\text { LPBC } \\
n=8(\%)\end{array}$ & $p$-Value & $\begin{array}{c}\text { No LPBC } \\
n=44(\%)\end{array}$ & $\begin{array}{c}\text { LPBC } \\
n=11(\%)\end{array}$ & $p$-Value \\
\hline STAT4 & & & $<0.001$ & & & 0.171 & & & 0.060 & & & 0.041 & & & 0.021 \\
\hline Low & $218(74.7)$ & $19(45.2)$ & & $111(72.1)$ & $4(50.0)$ & & $63(77.8)$ & $8(53.3)$ & & $11(84.6)$ & $3(37.5)$ & & $33(75.0)$ & $4(36.4)$ & \\
\hline High & $74(25.3)$ & $23(54.8)$ & & $43(27.9)$ & $4(50.0)$ & & $18(22.2)$ & $7(46.7)$ & & $2(15.4)$ & $5(62.5)$ & & $11(25.0)$ & 7 (63.6) & \\
\hline STAT6 & & & $<0.001$ & & & 0.180 & & & 0.016 & & & 0.310 & & & 0.182 \\
\hline Low & $228(78.1)$ & $24(57.1)$ & & $126(81.8)$ & $5(62.5)$ & & $59(72.8)$ & $6(40.0)$ & & $7(53.8)$ & $6(75.0)$ & & $36(81.8)$ & $7(63.6)$ & \\
\hline High & $64(21.9)$ & $18(42.9)$ & & $28(18.2)$ & $3(37.5)$ & & $22(27.2)$ & $9(60.0)$ & & $6(46.2)$ & $2(25.0)$ & & $8(18.2)$ & $4(36.4)$ & \\
\hline FOXP3 & & & 0.010 & & & 0.510 & & & 0.107 & & & 0.410 & & & 0.582 \\
\hline Low & $267(91.4)$ & $33(78.6)$ & & $144(93.5)$ & $7(87.5)$ & & $76(93.8)$ & $12(80.0)$ & & $10(76.9)$ & $5(62.5)$ & & $37(84.1)$ & $9(81.8)$ & \\
\hline High & $25(8.6)$ & $9(21.4)$ & & $10(6.5)$ & $1(12.5)$ & & $5(6.2)$ & $3(20.0)$ & & $3(23.1)$ & $3(37.5)$ & & $7(15.9)$ & $2(18.2)$ & \\
\hline CD8 & & & $<0.001$ & & & $<0.001$ & & & $<0.001$ & & & 0.002 & & & 0.005 \\
\hline Low & $279(95.5)$ & $13(31.0)$ & & $152(98.7)$ & $3(37.5)$ & & 75 (92.6) & $3(20.0)$ & & $11(84.6)$ & $1(12.5)$ & & $41(93.2)$ & $6(54.5)$ & \\
\hline High & $13(4.5)$ & $29(69.0)$ & & $2(1.3)$ & $5(62.5)$ & & $6(7.4)$ & $12(80.0)$ & & $2(15.4)$ & $7(87.5)$ & & $3(6.8)$ & $5(45.5)$ & \\
\hline CD68 & & & $<0.001$ & & & 0.003 & & & 0.002 & & & 0.112 & & & 0.023 \\
\hline Low & 177 (60.6) & $6(14.3)$ & & $100(64.9)$ & $1(12.5)$ & & $46(56.8)$ & $2(13.3)$ & & $6(46.2)$ & $1(12.5)$ & & $25(56.8)$ & $2(18.2)$ & \\
\hline High & $115(39.4)$ & $36(85.7)$ & & $54(35.1)$ & $7(87.5)$ & & $35(43.2)$ & $13(86.7)$ & & $7(53.8)$ & $7(87.5)$ & & $19(43.2)$ & $9(81.8)$ & \\
\hline CD163 & & & $<0.001$ & & & $<0.001$ & & & 0.001 & & & 0.310 & & & 0.023 \\
\hline Low & $215(73.6)$ & $8(19.0)$ & & $130(84.4)$ & $1(12.5)$ & & $54(66.7)$ & $3(20.0)$ & & $6(46.2)$ & $2(25.0)$ & & $25(56.8)$ & $2(18.2)$ & \\
\hline High & 77 (26.4) & $34(81.0)$ & & $24(15.6)$ & $7(87.5)$ & & $27(33.3)$ & $12(80.0)$ & & $7(53.8)$ & $6(75.0)$ & & $19(43.2)$ & $9(81.8)$ & \\
\hline
\end{tabular}




\subsection{Correlations among the Expression Statuses of Immune Cell Subtype-Related Proteins}

Significant positive correlations in expression statuses were observed among the immune cell subtype-related proteins (Supplementary Table S2) as follows: STAT4-STAT6 $(r=0.189, p=0.001)$, STAT4-FOXP3 $(r=0.229, p<0.001)$, STAT4-CD8 $(r=0.293, p<0.001)$, STAT4-CD68 $(r=0.140$, $p=0.010)$, STAT4-CD163 $(r=0.200, p<0.001)$, STAT6-FOXP3 $(r=0.303, p<0.001)$, STAT6-CD8 $(r=0.268, p<0.001)$, STAT6-CD68 $(r=0.276, p<0.010)$, STAT6-CD163 $(r=0.355, p<0.001)$, FOXP3-CD8 $(r=0.176, p=0.001)$, FOXP3-CD68 $(r=0.295, p<0.001)$, FOXP3-CD163 $(r=0.321, p<0.001)$, CD8-CD68 $(r=0.447, p<0.001), \mathrm{CD} 8-\mathrm{CD} 163(r=0.463, p<0.001)$, and CD68-CD163 $(r=0.485, p<0.001)$.

\subsection{Correlation between Clinicopathologic Parameters and the Expression Statuses of Immune Cell Subtype-Related Proteins}

The correlations between the proportions (\%) of ER and PR expression and the expression levels of immune cell subtype-related proteins (H-score or \%) were investigated. ER and PR expression, respectively, showed significant negative correlation with the expression of FOXP3 $(r=-0.197, p<0.001$ and $r=-0.156, p=0.004)$, CD68 $(r=-0.131, p=0.017$ and $r=-0.149, p=0.006)$, and CD163 $(r=-0.298$, $p<0.001$ and $r=-0.204, p<0.001)$. Stromal TIL (\%) and the expression levels of immune cell subtype-related proteins ( $\mathrm{H}$-score or $\%$ ) were significantly positively correlated for all immune cell subtype-related proteins (Table 4).

Table 4. Correlations between the proportions (\%) of ER, PR, and stromal TIL expression levels and immune cell subtype-related protein expression levels.

\begin{tabular}{ccccccc}
\hline Parameters & $\begin{array}{c}\text { STAT4 } \\
\text { H-Score }\end{array}$ & $\begin{array}{c}\text { STAT6 } \\
\text { H-Score }\end{array}$ & FOXP3 & CD8 & CD68 & CD163 \\
\hline ER & \multicolumn{7}{c}{ CD } & & & & \\
\hline$r$-coefficient & -0.086 & -0.148 & -0.197 & -0.046 & -0.131 & -0.298 \\
\hline$p$-value & 0.117 & 0.007 & $<0.001$ & 0.399 & 0.017 & $<0.001$ \\
\hline PR & & & & & \\
\hline$r$-coefficient & -0.051 & -0.083 & -0.156 & -0.105 & -0.149 & -0.204 \\
\hline$p$-value & 0.357 & 0.131 & 0.004 & 0.055 & 0.006 & $<0.001$ \\
\hline Stromal TIL & & & & & \\
\hline$r$-coefficient & 0.313 & 0.316 & 0.175 & 0.665 & 0.465 & 0.525 \\
\hline$p$-value & $<0.001$ & $<0.001$ & 0.001 & $<0.001$ & $<0.001$ & $<0.001$ \\
\hline & & TIL, tumor infiltrating lymphocyte. & &
\end{tabular}

When the relationships between clinicopathologic parameters with high- and low-expression of immune cell subtype-related proteins were assessed, higher histologic grade was associated with high STAT6, FOXP3, CD68, and CD163 expression levels. Furthermore, ER negativity was associated with high STAT6, FOXP3, and CD163 expression levels, whereas PR negativity and high Ki-67 labeling index (L.I.) were associated with high CD163 expression (Figure 2).

\subsection{Impact of Immune Cell Subtype-Related Protein Expression on Patient Prognosis}

Univariate Cox-proportional hazard analysis showed that a high CD8 expression level was associated with shorter disease-free survival (DFS) ( $p=0.003$; Table 5 and Figure 3A). Additionally, multivariate analysis revealed that a high CD8 expression level was an independent factor associated with shorter DFS (hazard ratio: 2.435, 95\% CI: 1.110-5.344, $p=0.049$; Table 6). 

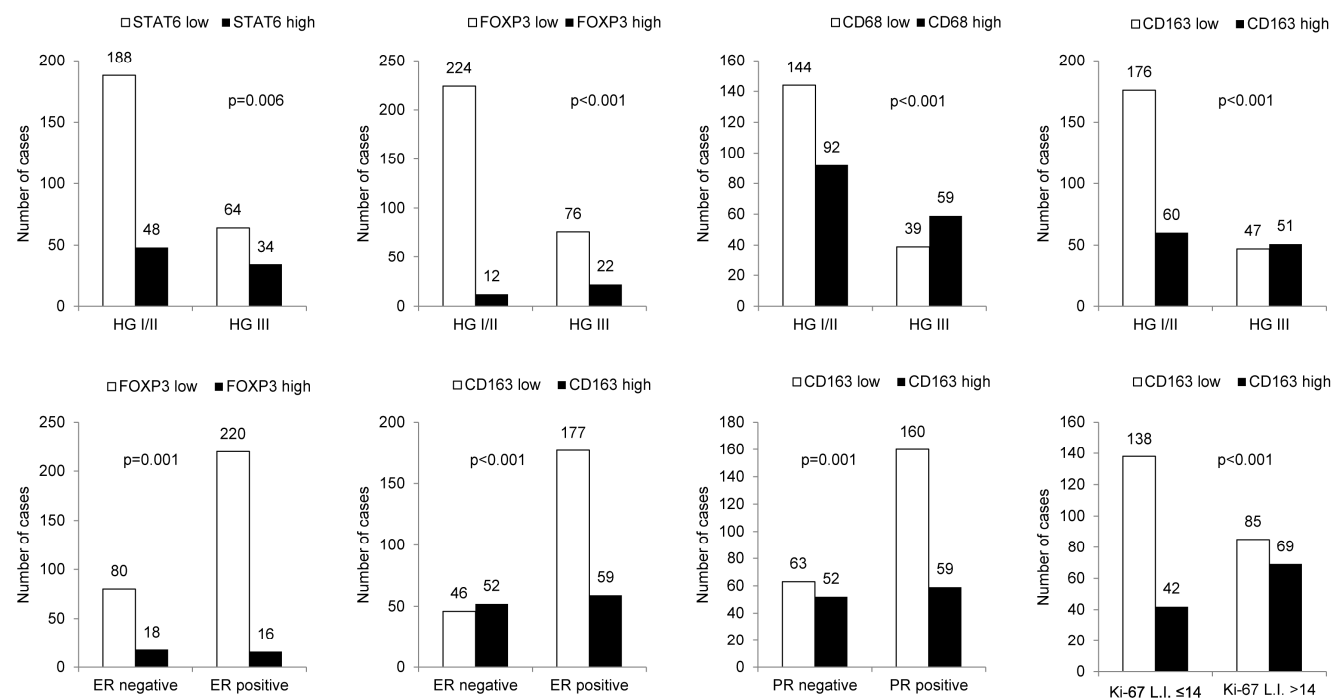

Figure 2. The relationship between clinicopathologic parameters and immune cell subtype-related protein expression. A higher histologic grade was associated with high expression levels of STAT6, FOXP3, CD68, and CD163; ER negativity was associated with high STAT6, FOXP3, and CD163 expression levels, whereas PR negativity and high Ki-67 L.I. were associated with high CD163 expression. HG: histologic grade; L.I.: labeling index.

Table 5. Univariate analysis of the impact of infiltrating immune cell subtype-related protein expression in breast cancers on disease-free survival and overall survival using the log-rank test.

\begin{tabular}{|c|c|c|c|c|c|}
\hline \multirow[t]{2}{*}{ Parameter } & \multirow{2}{*}{$\begin{array}{c}\text { Number } \\
\text { of Patients } \\
\text { /Recurrence/Death }\end{array}$} & \multicolumn{2}{|c|}{ Disease-Free Survival } & \multicolumn{2}{|c|}{ Overall Survival } \\
\hline & & $\begin{array}{c}\text { Mean Survival } \\
\text { (95\% CI) } \\
\text { Months }\end{array}$ & $p$-Value & $\begin{array}{c}\text { Mean Survival } \\
(95 \% \mathrm{CI}) \\
\text { Months }\end{array}$ & $p$-Value \\
\hline STAT4 & & & 0.346 & & 0.074 \\
\hline Low & $237 / 23 / 17$ & $101(98-104)$ & & $103(101-105)$ & \\
\hline High & $97 / 13 / 13$ & $98(93-103)$ & & $100(97-104)$ & \\
\hline STAT6 & & & 0.995 & & 0.054 \\
\hline Low & $252 / 27 / 27$ & 100 (97-103) & & 102 (99-104) & \\
\hline High & $82 / 9 / 3$ & $100(95-105)$ & & 105 (102-108) & \\
\hline FOXP3 & & & 0.672 & & 0.957 \\
\hline Low & $300 / 33 / 27$ & $100(97-102)$ & & $102(100-104)$ & \\
\hline High & $34 / 3 / 3$ & $101(94-108)$ & & $103(99-108)$ & \\
\hline CD8 & & & 0.003 & & 0.475 \\
\hline Low & $292 / 26 / 25$ & $101(99-104)$ & & 103 (101-105) & \\
\hline High & $42 / 10 / 5$ & $90(81-99)$ & & $99(94-105)$ & \\
\hline CD68 & & & 0.136 & & 0.629 \\
\hline Low & $183 / 15 / 15$ & $100(97-103)$ & & 101 (99-104) & \\
\hline High & $151 / 21 / 15$ & $99(95-102)$ & & $103(100-105)$ & \\
\hline CD163 & & & 0.714 & & 0.681 \\
\hline Low & $223 / 23 / 19$ & $100(97-103)$ & & 103 (101-105) & \\
\hline High & $111 / 13 / 11$ & $100(95-104)$ & & $102(99-105)$ & \\
\hline
\end{tabular}


(A)

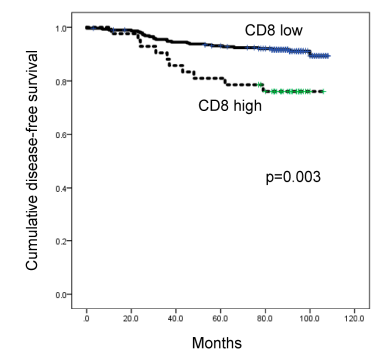

(D)

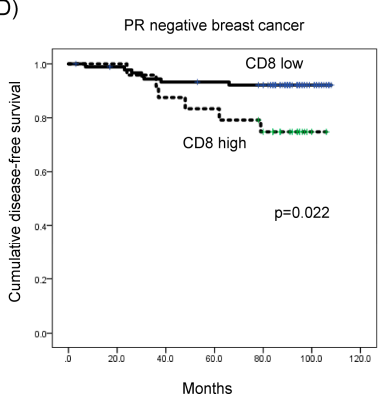

(B)

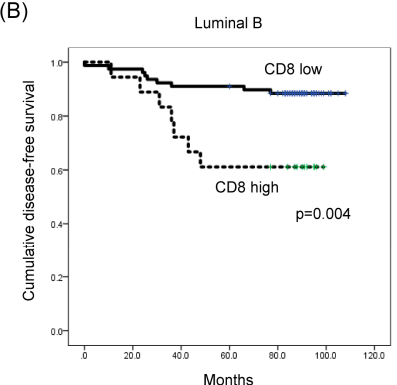

(E)

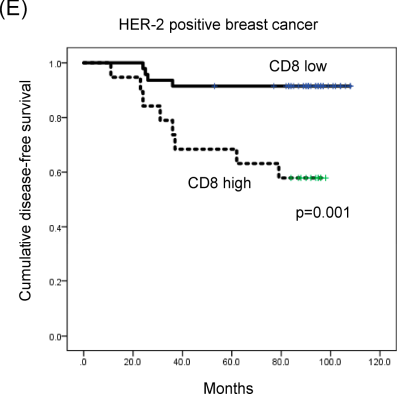

(C) ER positive breast cancer

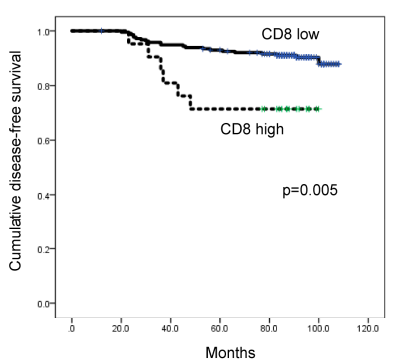

(F)

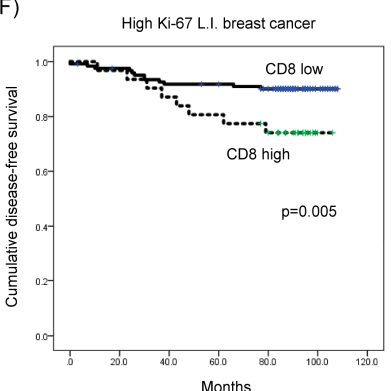

Figure 3. Impact of immune cell subtype-related protein expression on patient prognosis (disease-free survival, DFS). (A) High-level CD8 expression was associated with shorter DFS $(p=0.003)$. (B-F) High-level CD8 expression was associated with shorter DFS in luminal B type $(p=0.004)$, ER-positive $(p=0.005)$, PR-negative $(p=0.022)$, HER-2-positive $(p=0.001)$, and high Ki-67 L.I. (Ki-67 L.I. $>14 ; p=0.005)$ breast cancer. L.I.: labeling index.

Table 6. Multivariate analysis of the impact of prognostic factors of breast cancers on disease-free survival and overall survival.

\begin{tabular}{|c|c|c|c|c|c|c|}
\hline \multirow[t]{2}{*}{ Parameters } & \multicolumn{3}{|c|}{ Disease-Free Survival } & \multicolumn{3}{|c|}{ Overall Survival } \\
\hline & Hazard Ratio & $95 \% \mathrm{CI}$ & $p$-Value & Hazard Ratio & $95 \%$ CI & $p$-Value \\
\hline Age & & & 0.627 & & & 0.021 \\
\hline$\leq 50$ versus $>50$ & 1.185 & $0.597-2.353$ & & 2.418 & $1.145-5.108$ & \\
\hline Histologic grade & & & 0.220 & & & 0.201 \\
\hline I/II versus III & 1.674 & $0.735-3.814$ & & 1.784 & $0.734-4.338$ & \\
\hline T stage & & & 0.765 & & & 0.816 \\
\hline $\mathrm{T} 1$ versus $\mathrm{T} 2 / 3$ & 0.900 & $0.451-1.797$ & & 0.915 & $0.436-1.923$ & \\
\hline Lymph node metastasis & & & 0.022 & & & 0.163 \\
\hline No versus Yes & 2.247 & $1.125-4.488$ & & 1.708 & $0.805-3.626$ & \\
\hline ER status & & & 0.162 & & & 0.453 \\
\hline Negative versus Positive & 0.481 & $0.173-1.342$ & & 1.490 & $0.526-4.218$ & \\
\hline PR status & & & 0.893 & & & 0.840 \\
\hline Negative versus Positive & 0.943 & $0.404-2.203$ & & 1.096 & $0.452-2.656$ & \\
\hline HER-2 status & & & 0.216 & & & 0.450 \\
\hline Negative versus Positive & 1.628 & $0.752-3.525$ & & 1.400 & $0.585-3.348$ & \\
\hline Ki-67 L.I. & & & 0.539 & & & 0.489 \\
\hline$\leq 14$ versus $>14$ & 1.258 & $0.542-2.917$ & & 0.705 & $0.262-1.897$ & \\
\hline CD8 & & & 0.026 & & & 0.975 \\
\hline Low versus High & 2.435 & $1.110-5.344$ & & 0.984 & $0.355-2.728$ & \\
\hline
\end{tabular}

L.I., labeling index.

When a subgroup analysis was performed, high CD8 expression was associated with shorter DFS in luminal B type ( $p=0.004$; Figure 3B), as well as in ER-positive breast cancer $(p=0.005)$ (Figure 3C). Moreover, high CD8 expression was associated with shorter DFS in PR-negative, HER-2-positive, and high Ki-67 L.I. (Ki-67 L.I. $>14$ ) breast cancers $(p=0.022, p=0.001$, and $p=0.005$, respectively; Figure 3D-F). In high Ki-67 L.I. breast cancer, high-level STAT4 expression was associated with shorter overall survival (OS) ( $p=0.042$; Figure 4$)$. 


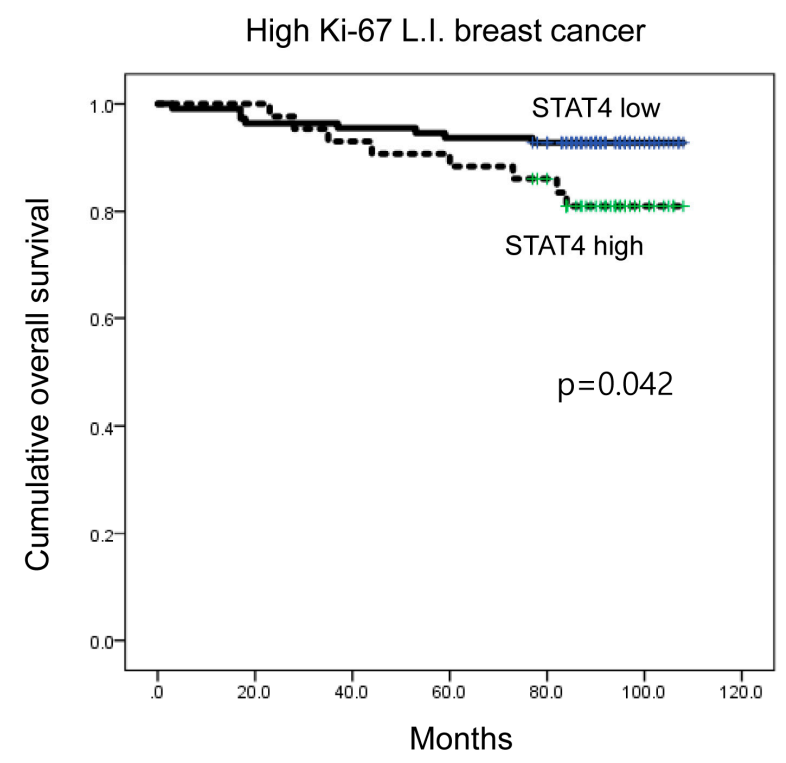

Figure 4. Impact of immune cell subtype-related protein expression on patient prognosis (overall survival, OS). In high Ki-67 L.I. breast cancer, high STAT4 expression was associated with shorter OS $(p=0.042)$. L.I.: labeling index.

\section{Discussion}

In this study, we aimed to identify subtypes of tumor-infiltrating immune cells in breast cancer and to investigate their implications. We found that the proportion of highly expressed STAT6, FOXP3, CD8, CD68, and CD163 proteins was the lowest in the luminal A type, but more frequent in the HER-2 type. Previous studies have reported that stromal TILs are less frequently found in the luminal type than in the HER-2 type and TNBC [21-24]. Additionally, the proportion of cases with LPBC, which is defined as cancer with $>50 \%$ stromal TILs, was also reported to be lower among the luminal type and higher among the HER-2 type and TNBC [22,23,25-27], which was identically observed in this study. Therefore, it can be said that in the luminal type, which has a small number of absolute immune cells, the number of immune cells that are positive for immune cell subtype-related proteins is low. Additionally, an analysis based on the molecular subtypes showed that the number of immune cells expressing CD8, CD68, and CD163 was higher in LPBC of luminal A type, indicating that the total number of stromal immune cell is an important determinant of immune cell subtype-related protein expression. However, among HER-2 type and TNBC, which generally have higher stromal TIL \% and LPBC, the proportion of highly expressed STAT6, FOXP3, CD8, CD68, and CD163 in HER-2 was observed to be high, and was found to be statistically significant for CD8 $(p=0.008)$. Based on these results, it can be suggested that HER-2 type and TNBC have different immune cell subtypes, even though they both present with increased stromal immune cell infiltration.

In a systematic review that analyzed infiltrating immune cell subtypes in breast cancer, CD8 was reported to exist similarly in TNBC and HER-2-positive breast cancer [27]. However, given that CD8 was included as a dichotomous variable (in absence/presence) in a study by Stanton et al. and that hormone receptor positive HER-2-positive breast cancer was included within HER-2-positive breast cancer, it seemed difficult to compare the results directly. Yet, in the case of FOXP3, when the results were analyzed by classification into low and high groups, high FOXP3 expression was reported in 70\% of TNBC and $67 \%$ of HER-2-positive breast cancer, which is similar to our study [27]. Nevertheless, as this study also included hormone receptor positive HER-2-positive breast cancer, the difference in the study groups should also be taken into consideration. Likewise, another study demonstrated that the number of FOXP3 and CD8 positive stromal TILs was higher in HER-2-positive breast cancer than TNBC in the invasive margin, showing similar results with this study [28]. However, Papaioannou et al. 
reported a contradictory result, indicating no difference in the T-cell subtype of TILs according to the molecular subtype, an observation that should be evaluated in further studies [29].

Considering the higher expression of the cytotoxic T-cell marker CD8 in HER-2-positive breast cancer compared to that in TNBC, a possible relationship between HER-2 amplification and T cell immunity could exist. As the HER-2 oncogene contains several major histocompatibility complex class I-restricted epitopes, it can be recognized by cytotoxic T lymphocytes (CTLs), such as CD8. Therefore, in HER-2 amplified cancer, many immune reactions could be present due to CTL infiltration of affected tissues [30,31].

Interestingly, we found that the expression of the tumor-associated macrophage (TAM) markers CD68 and CD163 was higher in HER-2-positive breast cancer. Although this association is not well studied [32-36], in an experiment that was performed using an animal model of HER-2-positive breast cancer, CCL2, which is produced by cancer and myeloid cells, attracted macrophages to upregulate Wnt-1 and downregulate E-cadherin, resulting in cancer dissemination. Additionally, HER-2 or another oncogenic signal could be responsible for the activation of mammary epithelial cells and macrophages [37-40], which seems to be relevant to the higher expression of TAM markers in HER-2-positive breast cancer.

Regarding patient prognosis, a high CD8 expression level was found to be an independent poor prognostic factor in all breast cancers and was associated with shorter DFS in luminal B, ER-positive, PR-negative, HER-2-positive, and high Ki-67 L.I. breast cancer. Although a previous study reported a contradictory result that increased $\mathrm{CD} 8^{+}$cells in TNBC were associated with better prognosis [15], the discordant result could be related to the fact that we investigated stromal CD8 ${ }^{+}$ immune cells, while the previous study investigated intratumoral $\mathrm{CD} 8^{+}$immune cells. Moreover, whether intratumoral $\mathrm{CD}^{+}$immune cells are a positive or negative prognostic factor remains unclear, as a study by Catacchio et al. has shown that intratumoral $\mathrm{CD}^{+}$immune cells are a negative prognostic factor in all breast cancers [41]. The association between $\mathrm{CD} 8^{+}$immune cells and breast cancer prognosis can be influenced by multiple factors, such as density, localization, and spatial distribution in TME [42]. Since we used tissue microarray to analyze tumor-infiltrating immune cells in this study, rather than whole sections for histological examination, samples may have been influenced by extraction bias during tissue microarray construction and may not be sufficient in assessing tumor heterogeneity. In addition, as the number of cases included in this study was relatively small, this could have also affected in the interpretation of study results. Thus, the additional studies are necessary for comprehensive evaluation and verification.

The clinical significance of this study is that TIL assessment could have an important implication in breast cancer treatment. For instance, it has been reported that TIL predicts responsiveness to specific therapeutic agents in breast cancer and predicts targeted therapy efficacy in specific molecular subtypes of breast cancer [43]. Therefore, there is a possibility that TIL could be utilized as a candidate biomarker for immune therapy, which is currently emphasized in breast cancer treatment. Recently, the expression of PD-L1, an important immune therapy biomarker, has been associated with TIL in breast cancer $[44,45]$. Moreover, PD-L1 infiltration was reported to be correlated with CD8 ${ }^{+}$immune cell infiltration in TNBC [46]. Importantly, when CD8 ${ }^{+}$immune cells are present in TIL and PD-L1 ${ }^{+}$ immune cells are present in breast cancer, immune checkpoint blockade has shown therapeutic benefit $[47,48]$.

Taken together, our results successfully demonstrated that the expression of the immune cell subtype-related proteins STAT6, FOXP3, CD8, CD68, and CD163 was different according to the molecular subtype of breast cancer. In particular, CD8 expression was found to be a prognostic factor. Our results strongly suggest that investigating TIL subgroups could provide useful prognostic and therapeutic information in breast cancer. However, future investigations are necessary for evaluating a possible difference in clinical responses to immune therapy depending on immune cell marker expression. 


\section{Materials and Methods}

\subsection{Patient Selection and Histologic Evaluation}

This study was performed using specimens from patients diagnosed with invasive ductal carcinoma after surgical removal of breast tissue at Yonsei University Severance Hospital, Seoul, South Korea from January 2000 to December 2006. Patients who received chemotherapy or hormone therapy prior to the surgery were excluded. This study was approved by the Institutional Review Board of Yonsei University Severance Hospital (14 November 2016; 4-2016-0832), which exempted informed consent from patients. All cases were reviewed by an experienced breast pathologist (Koo JS) using Hematoxylin \& Eosin (H \& E)-stained slides. Histological grading was assessed using the Nottingham grading system [49]. LPBC was defined as more than $50 \%$ of stromal TIL, as previously described [50]. Clinicopathologic parameters evaluated included patient age at initial diagnosis, lymph node metastasis, tumor recurrence, distant metastasis, and patient survival.

\subsection{Tissue Microarray}

Tissue microarrays were constructed using formalin-fixed and paraffin-embedded (FFPE) tissues from surgically resected breast cancer. Representative areas from the donor block were selected, extracted using a 3-mm-core punch machine, and placed in the donor block; cores with $>30 \%$ of the tumor cells were considered valid cores.

\subsection{Immunohistochemistry}

Immunohistochemistry (IHC) was performed using a BenchMark automated staining instrument (Ventana Medical System, Tucson, AZ, USA). Primary antibodies used for IHC staining are listed in Supplementary Table S3. Tissue samples were sectioned to $4 \mu \mathrm{m}$ thickness, deparaffinized in xylene, rehydrated in three graded alcohol chambers, and treated with 3\% hydrogen peroxide in methanol. For stain visualization, a 3,3'-Diaminobenzidine (DAB) detection kit (Ventana Medical System, Tucson, AZ, USA) was used.

\subsection{Immunohistochemistry Interpretation}

Immunohistochemical staining assessment via tissue microarrays was performed independently by two pathologists (Koo JS and Kim HM), as previously reported [51,52]. TILs that were positive for each immunohistochemical marker were scored for the stromal compartment. The percentage of stromal TILs was determined by dividing the area occupied by stromal TILs by the entire stromal tissue area (i.e., area possessed by mononuclear inflammatory cells divided by total intratumoral stromal area). TILs were evaluated within the borders of the invasive tumor and all mononuclear cells (including lymphocytes and plasma cells) were scored.

\subsection{Breast Cancer Molecular Classification}

We classified breast cancer phenotypes based on the IHC results for the hormone receptors (ER, PR, and HER-2) and Ki-67, and FISH results for HER-2 as follows [53]: luminal A type, ER- or/and PR-positive, HER-2-negative, and Ki-67 L.I. < 14\%; Luminal B type, (HER-2-negative) ER- or/and PR-positive, HER-2-negative, and Ki-67 L.I. $\geq 14 \%$; (HER-2-positive) ER- or/and PR-positive and HER-2 overexpressed or/and amplified; HER-2 type, ER- and PR-negative and HER-2 overexpressed or/and amplified; and TNBC type: ER-, PR-, and HER-2-negative.

\subsection{Statistical Analysis}

Data were analyzed using IBM SPSS Statistics for Windows, Version 21.0 (IBM Corp. Released 2012. Armonk, NY, USA). The $\chi^{2}$ or Fisher's exact test was used to compare the expression of tumor-infiltrating immune cells between breast cancer subgroups, as appropriate. A corrected $p$-value, 
determined using the Bonferroni multiple comparison procedure, was used for multiple comparisons. Statistical significance was set to $p<0.05$. Kaplan-Meier survival curves and log-rank test were employed to compare DFS and OS rates. Univariate and multivariate regression analyses were performed using the Cox proportional hazards model.

Supplementary Materials: Supplementary materials can be found at http://www.mdpi.com/1422-0067/21/12/4438/s1. Author Contributions: J.S.K. and H.M.K. conceived and designed the experiments; H.M.K. performed the experiments; J.S.K. and H.M.K. analyzed the data; J.S.K. contributed reagents/materials/analysis tools; and H.M.K. wrote the paper. All authors have read and agreed to the published version of the manuscript.

Funding: This study was supported by a faculty research grant from Yonsei University College of Medicine for 2016 (6-2016-0163).

Conflicts of Interest: The authors declare no conflict of interest.

\section{References}

1. Criscitiello, C.; Esposito, A.; Curigliano, G. Tumor-stroma crosstalk: Targeting stroma in breast cancer. Curr. Opin. Oncol. 2014, 26, 551-555. [CrossRef]

2. Hanahan, D.; Coussens, L.M. Accessories to the crime: Functions of cells recruited to the tumor microenvironment. Cancer Cell 2012, 21, 309-322. [CrossRef] [PubMed]

3. Ravelli, A.; Roviello, G.; Cretella, D.; Cavazzoni, A.; Biondi, A.; Cappelletti, M.R.; Zanotti, L.; Ferrero, G.; Ungari, M.; Zanconati, F.; et al. Tumor-infiltrating lymphocytes and breast cancer: Beyond the prognostic and predictive utility. Tumour Biol. J. Int. Soc. Oncodev. Biol. Med. 2017, 39. [CrossRef] [PubMed]

4. Qiu, S.Q.; Waaijer, S.J.H.; Zwager, M.C.; de Vries, E.G.E.; van der Vegt, B.; Schröder, C.P. Tumor-associated macrophages in breast cancer: Innocent bystander or important player? Cancer Treat. Rev. 2018, 70, 178-189. [CrossRef]

5. Speiser, D.E.; Ho, P.C.; Verdeil, G. Regulatory circuits of T cell function in cancer. Nat. Rev. Immunol. 2016, 16, 599-611. [CrossRef]

6. Zhang, Y.; Zhang, Y.; Gu, W.; Sun, B. TH1/TH2 cell differentiation and molecular signals. Adv. Exp. Med. Biol. 2014, 841, 15-44. [PubMed]

7. Rao, A.; Avni, O. Molecular aspects of T-cell differentiation. Br. Med. Bull. 2000, 56, 969-984. [CrossRef]

8. Najafi, M.; Farhood, B.; Mortezaee, K. Contribution of regulatory T cells to cancer: A review. J. Cell. Physiol. 2019, 234, 7983-7993. [CrossRef]

9. Taniuchi, I. CD4 Helper and CD8 Cytotoxic T Cell Differentiation. Annu. Rev. Immunol. 2018, 36, 579-601. [CrossRef]

10. Troiano, G.; Caponio, V.C.A.; Adipietro, I.; Tepedino, M.; Santoro, R.; Laino, L.; Lo Russo, L.; Cirillo, N.; Lo Muzio, L. Prognostic significance of CD68(+) and CD163(+) tumor associated macrophages in head and neck squamous cell carcinoma: A systematic review and meta-analysis. Oral Oncol. 2019, 93, 66-75. [CrossRef]

11. Lakhani, S.R.; International Agency for Research on Cancer; World Health Organization. WHO Classification of Tumours of the Breast; International Agency for Research on Cancer: Lyon, France, 2012.

12. Solinas, C.; Carbognin, L.; De Silva, P.; Criscitiello, C.; Lambertini, M. Tumor-infiltrating lymphocytes in breast cancer according to tumor subtype: Current state of the art. Breast (Edinb. Scotl.) 2017, 35, 142-150. [CrossRef] [PubMed]

13. Salgado, R.; Denkert, C.; Campbell, C.; Savas, P.; Nuciforo, P.; Aura, C.; de Azambuja, E.; Eidtmann, H.; Ellis, C.E.; Baselga, J.; et al. Tumor-infiltrating lymphocytes and associations with pathological complete response and event-free survival in HER2-positive early-stage breast cancer treated with lapatinib and trastuzumab: A secondary analysis of the NeoALTTO trial. JAMA Oncol. 2015, 1, 448-454. [CrossRef] [PubMed]

14. Ibrahim, E.M.; Al-Foheidi, M.E.; Al-Mansour, M.M.; Kazkaz, G.A. The prognostic value of tumor-infiltrating lymphocytes in triple-negative breast cancer: A meta-analysis. Breast Cancer Res. Treat. 2014, 148, 467-476. [CrossRef]

15. Liu, S.; Lachapelle, J.; Leung, S.; Gao, D.; Foulkes, W.D.; Nielsen, T.O. CD8 ${ }^{+}$lymphocyte infiltration is an independent favorable prognostic indicator in basal-like breast cancer. Breast Cancer Res. BCR 2012, 14, R48. [CrossRef] 
16. Kim, S.T.; Jeong, H.; Woo, O.H.; Seo, J.H.; Kim, A.; Lee, E.S.; Shin, S.W.; Kim, Y.H.; Kim, J.S.; Park, K.H. Tumor-infiltrating lymphocytes, tumor characteristics, and recurrence in patients with early breast cancer. Am. J. Clin. Oncol. 2013, 36, 224-231. [CrossRef]

17. Wang, K.; Shen, T.; Siegal, G.P.; Wei, S. The CD4/CD8 ratio of tumor-infiltrating lymphocytes at the tumor-host interface has prognostic value in triple-negative breast cancer. Hum. Pathol. 2017, 69, 110-117. [CrossRef]

18. Sharma, M.; Beck, A.H.; Webster, J.A.; Espinosa, I.; Montgomery, K.; Varma, S.; van de Rijn, M.; Jensen, K.C.; West, R.B. Analysis of stromal signatures in the tumor microenvironment of ductal carcinoma in situ. Breast Cancer Res. Treat. 2010, 123, 397-404. [CrossRef]

19. Campbell, M.J.; Baehner, F.; O’Meara, T.; Ojukwu, E.; Han, B.; Mukhtar, R.; Tandon, V.; Endicott, M.; Zhu, Z.; Wong, J.; et al. Characterizing the immune microenvironment in high-risk ductal carcinoma in situ of the breast. Breast Cancer Res. Treat. 2017, 161, 17-28. [CrossRef]

20. Thompson, E.; Taube, J.M.; Elwood, H.; Sharma, R.; Meeker, A.; Warzecha, H.N.; Argani, P.; Cimino-Mathews, A.; Emens, L.A. The immune microenvironment of breast ductal carcinoma in situ. Mod. Pathol. 2016, 29, 249-258. [CrossRef] [PubMed]

21. Dieci, M.V.; Griguolo, G.; Miglietta, F.; Guarneri, V. The immune system and hormone-receptor positive breast cancer: Is it really a dead end? Cancer Treat. Rev. 2016, 46, 9-19. [CrossRef] [PubMed]

22. Loi, S.; Sirtaine, N.; Piette, F.; Salgado, R.; Viale, G.; Van Eenoo, F.; Rouas, G.; Francis, P.; Crown, J.P.; Hitre, E.; et al. Prognostic and predictive value of tumor-infiltrating lymphocytes in a phase III randomized adjuvant breast cancer trial in node-positive breast cancer comparing the addition of docetaxel to doxorubicin with doxorubicin-based chemotherapy: BIG 02-98. J. Clin. Oncol. 2013, 31, 860-867. [CrossRef]

23. Dieci, M.V.; Mathieu, M.C.; Guarneri, V.; Conte, P.; Delaloge, S.; Andre, F.; Goubar, A. Prognostic and predictive value of tumor-infiltrating lymphocytes in two phase III randomized adjuvant breast cancer trials. Ann. Oncol. Off. J. Eur. Soc. Med. Oncol. 2015, 26, 1698-1704. [CrossRef] [PubMed]

24. Loi, S.; Michiels, S.; Salgado, R.; Sirtaine, N.; Jose, V.; Fumagalli, D.; Kellokumpu-Lehtinen, P.L.; Bono, P.; Kataja, V.; Desmedt, C.; et al. Tumor infiltrating lymphocytes are prognostic in triple negative breast cancer and predictive for trastuzumab benefit in early breast cancer: Results from the FinHER trial. Ann. Oncol. Off. J. Eur. Soc. Med. Oncol. 2014, 25, 1544-1550. [CrossRef] [PubMed]

25. Perez, E.A.; Ballman, K.V.; Tenner, K.S.; Thompson, E.A.; Badve, S.S.; Bailey, H.; Baehner, F.L. Association of stromal tumor-infiltrating lymphocytes with recurrence-free survival in the N9831 adjuvant trial in patients with early-stage HER2-positive breast cancer. JAMA Oncol. 2016, 2, 56-64. [CrossRef] [PubMed]

26. Pruneri, G.; Vingiani, A.; Bagnardi, V.; Rotmensz, N.; De Rose, A.; Palazzo, A.; Colleoni, A.M.; Goldhirsch, A.; Viale, G. Clinical validity of tumor-infiltrating lymphocytes analysis in patients with triple-negative breast cancer. Ann. Oncol. Off. J. Eur. Soc. Med. Oncol. 2016, 27, 249-256. [CrossRef] [PubMed]

27. Stanton, S.E.; Adams, S.; Disis, M.L. Variation in the incidence and magnitude of tumor-infiltrating lymphocytes in breast cancer subtypes: A systematic review. JAMA Oncol. 2016, 2, 1354-1360. [CrossRef]

28. Glajcar, A.; Szpor, J.; Hodorowicz-Zaniewska, D.; Tyrak, K.E.; Okon, K. The composition of T cell infiltrates varies in primary invasive breast cancer of different molecular subtypes as well as according to tumor size and nodal status. Virchows Arch. 2019, 475, 13-23. [CrossRef] [PubMed]

29. Papaioannou, E.; Sakellakis, M.; Melachrinou, M.; Tzoracoleftherakis, E.; Kalofonos, H.; Kourea, E. A standardized evaluation method for FOXP3+ Tregs and CD8 ${ }^{+}$T-cells in breast carcinoma: Association with breast carcinoma subtypes, stage and prognosis. Anticancer Res. 2019, 39, 1217-1232. [CrossRef]

30. Sotiropoulou, P.A.; Perez, S.A.; Iliopoulou, E.G.; Missitzis, I.; Voelter, V.; Echner, H.; Baxevanis, C.N.; Papamichail, M. Cytotoxic T-cell precursor frequencies to HER-2 (369-377) in patients with HER-2/neu-positive epithelial tumours. Br. J. Cancer 2003, 89, 1055-1061. [CrossRef] [PubMed]

31. Sotiropoulou, P.A.; Perez, S.A.; Voelter, V.; Echner, H.; Missitzis, I.; Tsavaris, N.B.; Papamichail, M.; Baxevanis, C.N. Natural CD8 ${ }^{+}$T-cell responses against MHC class I epitopes of the HER-2/ neu oncoprotein in patients with epithelial tumors. Cancer Immunol. Immunother. 2003, 52, 771-779. [CrossRef] [PubMed]

32. Mahmoud, S.M.; Lee, A.H.; Paish, E.C.; Macmillan, R.D.; Ellis, I.O.; Green, A.R. Tumour-infiltrating macrophages and clinical outcome in breast cancer. J. Clin. Pathol. 2012, 65, 159-163. [CrossRef]

33. Gwak, J.M.; Jang, M.H.; Kim, D.I.; Seo, A.N.; Park, S.Y. Prognostic value of tumor-associated macrophages according to histologic locations and hormone receptor status in breast cancer. PLoS ONE 2015, 10, e0125728. [CrossRef] [PubMed] 
34. Medrek, C.; Ponten, F.; Jirstrom, K.; Leandersson, K. The presence of tumor associated macrophages in tumor stroma as a prognostic marker for breast cancer patients. BMC Cancer 2012, 12, 306. [CrossRef] [PubMed]

35. Lindsten, T.; Hedbrant, A.; Ramberg, A.; Wijkander, J.; Solterbeck, A.; Eriksson, M.; Delbro, D.; Erlandsson, A. Effect of macrophages on breast cancer cell proliferation, and on expression of hormone receptors, uPAR and HER-2. Int. J. Oncol. 2017, 51, 104-114. [CrossRef] [PubMed]

36. Jeong, H.; Hwang, I.; Kang, S.H.; Shin, H.C.; Kwon, S.Y. Tumor-associated macrophages as potential prognostic biomarkers of invasive breast cancer. J. Breast Cancer 2019, 22, 38-51. [CrossRef] [PubMed]

37. Linde, N.; Casanova-Acebes, M.; Sosa, M.S.; Mortha, A.; Rahman, A.; Farias, E.; Harper, K.; Tardio, E.; Reyes Torres, I.; Jones, J.; et al. Macrophages orchestrate breast cancer early dissemination and metastasis. Nat. Commun. 2018, 9, 21. [CrossRef]

38. Van Nguyen, A.; Pollard, J.W. Colony stimulating factor-1 is required to recruit macrophages into the mammary gland to facilitate mammary ductal outgrowth. Dev. Biol. 2002, 247, 11-25. [CrossRef]

39. Gouon-Evans, V.; Rothenberg, M.E.; Pollard, J.W. Postnatal mammary gland development requires macrophages and eosinophils. Development 2000, 127, 2269-2282.

40. Gouon-Evans, V.; Lin, E.Y.; Pollard, J.W. Requirement of macrophages and eosinophils and their cytokines/chemokines for mammary gland development. Breast Cancer Res. BCR 2002, 4, 155-164. [CrossRef]

41. Catacchio, I.; Silvestris, N.; Scarpi, E.; Schirosi, L.; Scattone, A.; Mangia, A. Intratumoral, rather than stromal, $\mathrm{CD}^{+} \mathrm{T}$ cells could be a potential negative prognostic marker in invasive breast cancer patients. Transl. Oncol. 2019, 12, 585-595. [CrossRef]

42. Fortis, S.P.; Sofopoulos, M.; Sotiriadou, N.N.; Haritos, C.; Vaxevanis, C.K.; Anastasopoulou, E.A.; Janssen, N.; Arnogiannaki, N.; Ardavanis, A.; Pawelec, G.; et al. Differential intratumoral distributions of CD8 and CD163 immune cells as prognostic biomarkers in breast cancer. J. Immunother. Cancer 2017, 5, 39. [CrossRef] [PubMed]

43. Lambertini, M.; Ponde, N.F.; Solinas, C.; de Azambuja, E. Adjuvant trastuzumab: A 10-year overview of its benefit. Expert Rev. Anticancer Ther. 2017, 17, 61-74. [CrossRef] [PubMed]

44. Wimberly, H.; Brown, J.R.; Schalper, K.; Haack, H.; Silver, M.R.; Nixon, C.; Bossuyt, V.; Pusztai, L.; Lannin, D.R.; Rimm, D.L. PD-L1 Expression correlates with tumor-infiltrating lymphocytes and response to neoadjuvant chemotherapy in breast cancer. Cancer Immunol. Res. 2015, 3, 326-332. [CrossRef]

45. Schalper, K.A.; Velcheti, V.; Carvajal, D.; Wimberly, H.; Brown, J.; Pusztai, L.; Rimm, D.L. In situ tumor PD-L1 mRNA expression is associated with increased TILs and better outcome in breast carcinomas. Clin. Cancer Res. 2014, 20, 2773-2782. [CrossRef] [PubMed]

46. Mittendorf, E.A.; Philips, A.V.; Meric-Bernstam, F.; Qiao, N.; Wu, Y.; Harrington, S.; Su, X.; Wang, Y.; Gonzalez-Angulo, A.M.; Akcakanat, A.; et al. PD-L1 expression in triple-negative breast cancer. Cancer Immunol. Res. 2014, 2, 361-370. [CrossRef] [PubMed]

47. Schmid, P.; Cruz, C.; Braiteh, F.S.; Eder, J.P.; Tolaney, S.; Kuter, I.; Nanda, R.; Chung, C.; Cassier, P.; Delord, J.-P.; et al. Abstract 2986: Atezolizumab in metastatic TNBC (mTNBC): Long-term clinical outcomes and biomarker analyses. Cancer Res. 2017, 77 (Suppl. S13), 2986.

48. Dirix, L.; Takacs, I.; Nikolinakos, P.; Jerusalem, G.; Arkenau, H.-T.; Hamilton, E.; von Heydebreck, A.; Grote, H.-J.; Chin, K.; Lippman, M. Abstract S1-04: Avelumab (MSB0010718C), an anti-PD-L1 antibody, in patients with locally advanced or metastatic breast cancer: A phase Ib JAVELIN solid tumor trial. Cancer Res. 2016, 76 (Suppl. S4), S1-04.

49. Elston, C.W.; Ellis, I.O. Pathological prognostic factors in breast cancer. I. The value of histological grade in breast cancer: Experience from a large study with long-term follow-up. Histopathology 1991, 19, 403-410. [CrossRef]

50. Ohtani, H.; Mori-Shiraishi, K.; Nakajima, M.; Ueki, H. Defining lymphocyte-predominant breast cancer by the proportion of lymphocyte-rich stroma and its significance in routine histopathological diagnosis. Pathol. Int. 2015, 65, 644-651. [CrossRef]

51. Salgado, R.; Denkert, C.; Demaria, S.; Sirtaine, N.; Klauschen, F.; Pruneri, G.; Wienert, S.; Van den Eynden, G.; Baehner, F.L.; Penault-Llorca, F.; et al. The evaluation of tumor-infiltrating lymphocytes (TILs) in breast cancer: Recommendations by an International TILs Working Group 2014. Ann. Oncol. Off. J. Eur. Soc. Med. Oncol. 2015, 26, 259-271. [CrossRef]

52. Hendry, S.; Salgado, R.; Gevaert, T.; Russell, P.A.; John, T.; Thapa, B.; Christie, M.; van de Vijver, K.; Estrada, M.V.; Gonzalez-Ericsson, P.I.; et al. Assessing tumor-infiltrating lymphocytes in solid tumors: A practical review for pathologists and proposal for a standardized method from the international immunooncology biomarkers working group: Part 1: Assessing the host immune response, TILs in 
invasive breast carcinoma and ductal carcinoma in situ, metastatic tumor deposits and areas for further research. Adv. Anat. Pathol. 2017, 24, 235-251. [PubMed]

53. Goldhirsch, A.; Wood, W.C.; Coates, A.S.; Gelber, R.D.; Thurlimann, B.; Senn, H.J. Strategies for subtypes-dealing with the diversity of breast cancer: Highlights of the St. Gallen International Expert Consensus on the Primary Therapy of Early Breast Cancer 2011. Ann. Oncol. Off. J. Eur. Soc. Med. Oncol. 2011, 22, 1736-1747. [CrossRef] [PubMed]

(C) 2020 by the authors. Licensee MDPI, Basel, Switzerland. This article is an open access article distributed under the terms and conditions of the Creative Commons Attribution (CC BY) license (http://creativecommons.org/licenses/by/4.0/). 